University of Nebraska - Lincoln

DigitalCommons@University of Nebraska - Lincoln

Faculty Publications, Department of Child, Youth, and Family Studies

Child, Youth, and Family Studies, Department of

October 2000

\title{
Integrating Visual and Verbal Literacies in the Early Childhood Classroom
}

Carolyn P. Edwards

University of Nebraska-Lincoln, cedwards1@unl.edu

Linda Mayo Willis

University of Nebraska-Lincoln

Follow this and additional works at: https://digitalcommons.unl.edu/famconfacpub

Part of the Family, Life Course, and Society Commons

Edwards, Carolyn P. and Willis, Linda Mayo, "Integrating Visual and Verbal Literacies in the Early Childhood Classroom " (2000). Faculty Publications, Department of Child, Youth, and Family Studies. 6.

https://digitalcommons.unl.edu/famconfacpub/6

This Article is brought to you for free and open access by the Child, Youth, and Family Studies, Department of at DigitalCommons@University of Nebraska - Lincoln. It has been accepted for inclusion in Faculty Publications, Department of Child, Youth, and Family Studies by an authorized administrator of DigitalCommons@University of Nebraska - Lincoln. 


\section{Integrating Visual and Verbal Literacies in the Early Childhood Classroom *}

Carolyn Pope Edwards and Linda Mayo Willis

Department of Family and Consumer Sciences, University of Nebraska-Lincoln

\section{Introduction}

Young children have the strong desire to use all of the communicative tools their cultures and families offer them. They want to be able to do all of the things that the powerful people they admire can do, including talking, writing, drawing, using the computer, and otherwise creating and sharing ideas, memories, solutions, even jokes and feelings. Today, we live in a time when the communicative tools are changing rapidly, practically exploding before our eyes in terms of the formats and media available to us in complex combinations not seen before. What do these technological changes mean for how we can support children's development toward literacy?

*Published in Early Childhood Education Journal 27:4 (2000), pp. 259265. Copyright $@ 2000$ Human Sciences Press; used by permission.
"Literacy" can be defined as the ability to read and write messages in the service of three goals: (a) recording and preserving experiences; (b) reflecting upon, exploring, and extending one's thoughts and feelings; and (c) communicating and sharing ideas with others. Although literacy is usually thought of with respect to the written word, it can also be considered more broadly applying to other conventionalized systems of representation and communication.

The ability to read and write is crucial to young children's emerging cognitive development and academic learning in school, as well as throughout later life. The path toward literacy has its foundations during infancy (with the first forms of gestural and verbal expression) but becomes really evident during the preschool period, when still preliterate children assimilate new skills such as picture and letter recognition and take first steps toward learning to decode and write simple messages. Their early experiences with symbolic media shape their motivations and orientation toward all aspects of reading and writing. For young children it is most natural to bring together and combine symbolic forms when they seek to express themselves, for example, to combine drawing with writing, or gesture with speaking. As they begin to grasp the basic functions of literacy, they become engaged in meaningmaking that alternates between and/or combines oral language, written and printed symbols, drawings, and other formats. Because infants and young children are global and holistic in their ways of perceiving, conceiving, and communicating (Lally, 1998), they prefer an integrated approach as they move toward literacy, as seen in the following example:

One day while preoccupied by typing at the computer.

Rebecca's mother received an unusual communication-her very first "letter" ever from her 4-year-old. 
Sitting engrossed at her machine, this mother found a small square of paper thrust before her face. She studied a little pencil drawing of a figure which seemed to have a huge upthrust arm ending in a very long finger pointing forward Underneath the figure was printed the bold letters: NO. Rebecca's surprised mother asked her daughter what this was. and the little girl replied. "I want you to stop typing!"

Rebecca's drawing actually depends on several modes of communication, and the integration is typical of young children. The child wants to send as clear and strong a message as possible. As she watches her mother typing and thinks about her feelings and what she wants to say. she probably first expresses her message to herself by means of a gesture (shaking her arm and forefinger in a negative way). She then takes the next step of representing the gesture through another method of communicating that she thinks may gain her more respect-drawing-and "writes" her gesture in a picture. Finally, she wants to embellish her message with a speech, but not able to write a lengthy verbal message ("1 want you to stop typing"), she does her best with a big summation, "NO."

Thus, it is natural for young children to seek to master and use many alternative "literacies," or avenues of symbolic representation offered by their culture, such as drawing, painting, gesture, construction, dramatic play, and words. Certainly, each young child's own unique learning style may cause him or her to understand best and prefer some forms of symbolic representation over others. As Gardner (1983) and others have argued, intelligence is multifaceted and involves multiple ways of representing experience and solving problems. Each child develops an individual learning style and profile of intellectual strengths that causes him or her to respond best or most rap- idly to some modalities and frameworks rather than others. Nevertheless, most children (and many adults) actually seek out a mixed presentation, with information presented through two or more modalities, as in songs, chants, marches, rituals, dramas, and games. Children do not systematically segment their experience for analytic consideration. Richer, rounder, multidimensional experiences are more memorable than simplified, flatter, single-dimensional ones.

Not only are young children usually more motivated and competent when they approach tasks holistically but, in fact, our contemporary world demands more and more an integrated approach to literacy (Garrett-Petts \& Lawrence, 1996). Visual images (photographs, drawings, diagrams, paintingsboth moving and still) pervade our modern experience, and they are often combined with auditory images. Much of what we know about the world comes to us through such complex multimedia, and new technologies invite ever more creative combinations of formats and symbol systems. Indeed, the ability to put together and integrate words and images, sights and sounds, is demanded of every producer and every consumer of a television show, movie, magazine, book, computer game, exhibition, concert, or theater production.

Some people deplore these developments, thinking about how easily children are captivated by television, music videos, comic books, and computer games, so that book reading suffers. These critics feel that consumers, in general, tend to be misled or diminished in imagination by modern media. But other people seem enthralled and enchanted, like the young techno-wizards themselves.

Indeed, some modern literacy scholars, such as GarrettPetts and Lawrence (1996), propose a new sort of cultural literacy that is profoundly interdisciplinary. They argue that mix- 
ing media is a valid communication strategy that demands highly educated consumers and provides new ways to learn about the world. For example, in reading an illustrated story while listening to the sound track on headphones, the child must interpret the written words partially in terms of the pictorial illustrations, spoken words, and musical accompaniment. The words add to the meaning of the music and pictures, and vice versa; the total is greater than the sum of the parts. As children become more and more sophisticated readers, they come to appreciate, for example, how illustrations can enhance the text-to give examples, to add humor, to provide emphasis, or otherwise to change the text in significant ways, rhetorical or critical. Garrett-Petts and Lawrence define this as "learning to read the third text" (where the "first text" is the written word, the "second text" is the images, and the "third text" is the meaning created by their interaction). In their view, it is the teacher's responsibility to nurture this facility in young learners. They go on to suggest that the educators in one context. Reggio Emilia, Italy, have offered us a particularly articulate vision of how to create such an integrated curriculum.

\section{The Reggio Emilia Approach}

The Reggio Emilia approach to early childhood education is known throughout the world for its innovative, integrated curriculum (Malaguzzi, 1998). Drawing on Italian cultural strengths in design and the arts, the Reggio approach serves to enhance the symbolic, expressive, and communicative skills of very young children. Teachers provide children with systematic and graded opportunities to become fluent and confident in many avenues and formats, what they call metaphorically

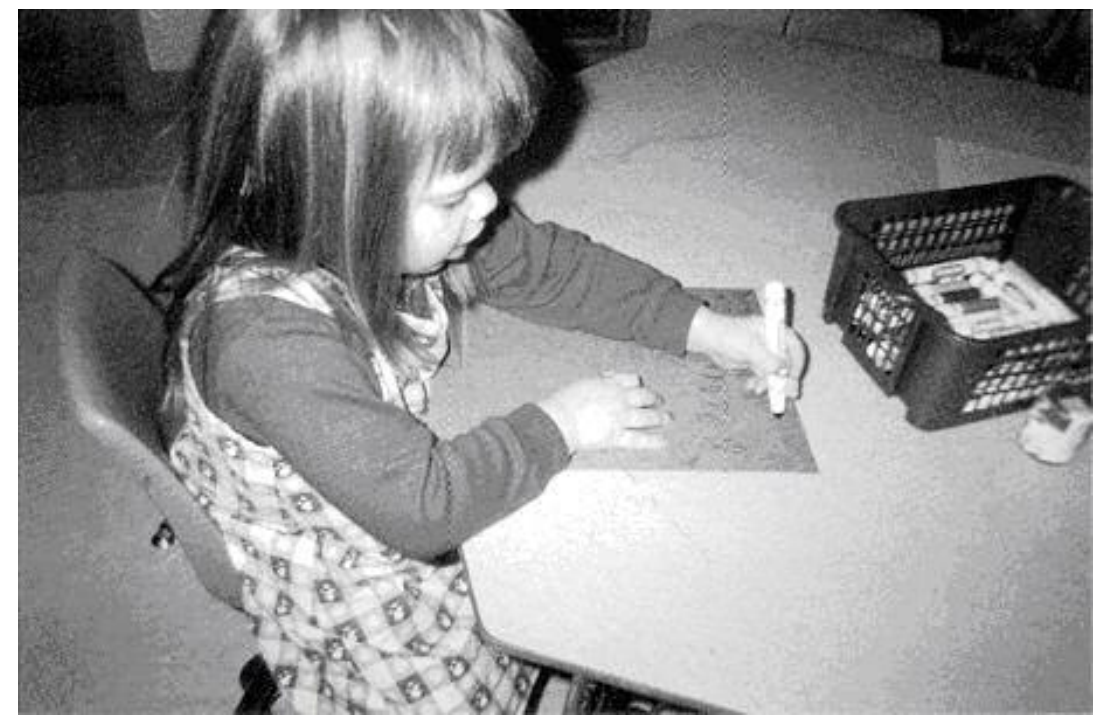

Figure 1. Mykala, a 4-year-old girl, writes her very first letter from school to home. Her letter consists of curlicues that closely resemble letters. She is able to "read" the message to her teacher. Courtesy Ruth Staples Child Development Laboratory School. University of Nebraska, Lincoln.

the "100 languages of children." (Reggio Children, 1996). They use this metaphor in a rather free-wheeling way. Sometimes the term refers to children's invented notations and sometimes to our cultural heritage of formal symbolic systems (such as music, painting, and natural language) that have distinct rules of usage and ways of conveying meaning (Gardner, 1998). At other times the term refers simply to contexts or manners of communication that result in special "child codes" (for example, "peer talk," or "pretend play"). But their key point, in either case, is that the "languages" are not and should not be isolated from one another, like separate compartments in a storage garage. Rather, the image is of an open house, full of 
light due to many exterior and interior windows and connecting hallways and doors. Each language becomes more powerful insofar as it becomes integrated with the others. (See Figs. 1, 2, 3.)

\section{What Different Symbolic Media Afford}

In considering children's use of different media, their growing competence in different symbolic languages, several questions arise. The first concerns what is the child's experience as he or she uses each symbol system. The second concerns what children think about and learn as they move from one to another and construct knowledge about that process. The third focuses directly on the qualities and properties of each medium and how these influence what can and does unfold in the teaching/learning context.

As an example, let us consider for a moment a child who has been playing house with her friends and decides she wants to paint a picture of this house. As she uses her brush, the paint flows onto the paper in bold colorful lines and the child relives the inner experience of having "my house"-something big and beautiful that gives her a strong sense of belonging. As she stops to admire her painting, she looks at the closed door and begins to think about the act of going inside her house. Now she experiences a problem-wanting to open the door. She does not know how to paint a door that can open, so she decides to use clay to make a new house. She spends a great deal of time learning how to create a little slab of clay for a door and a "frame" of clay around it. She enjoys manipulating this door even though the clay tends to squash into the clay of the door frame every time she closes it. She realizes that she

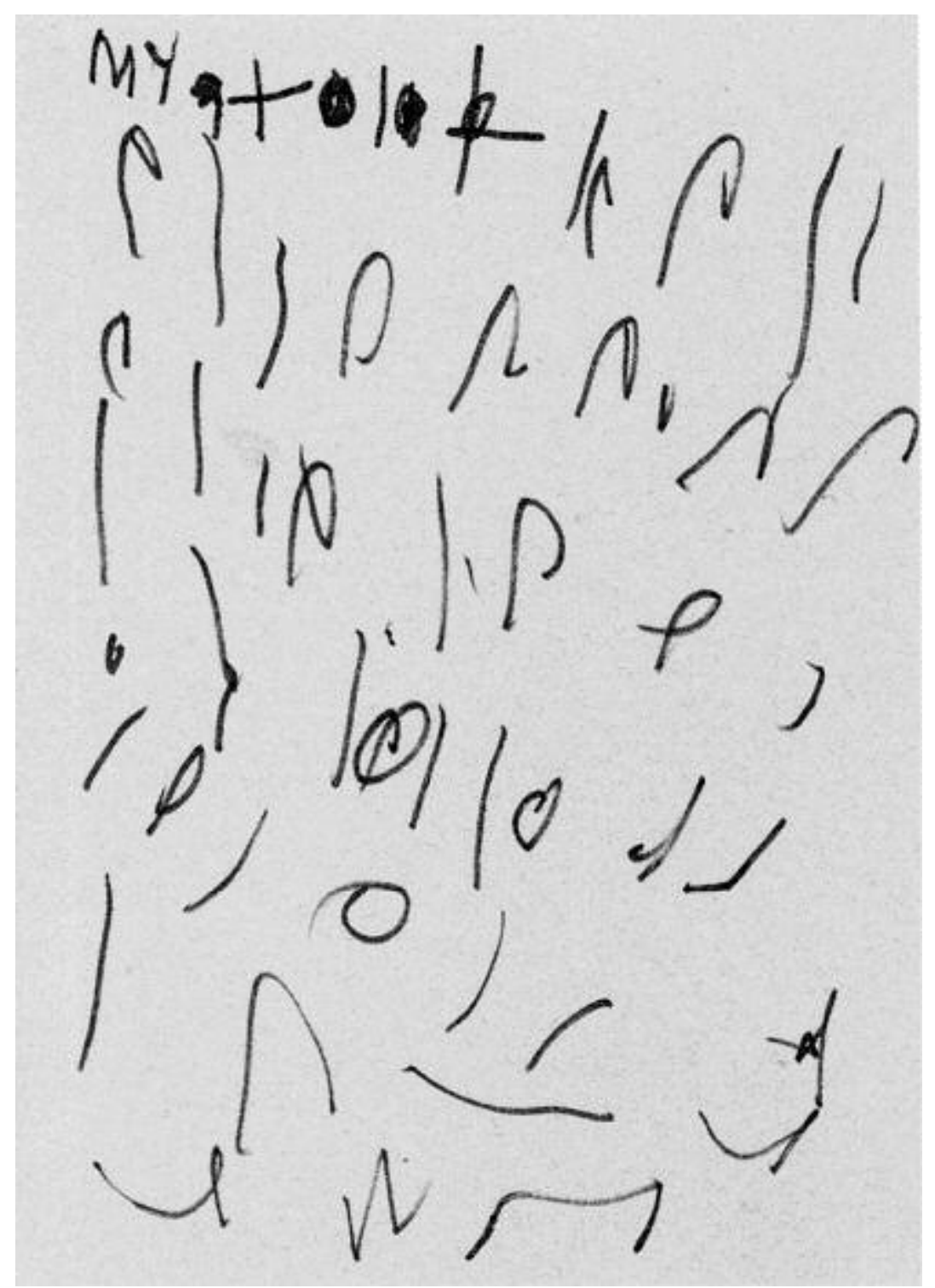

Figure 2. The invented notation of Mykala. 


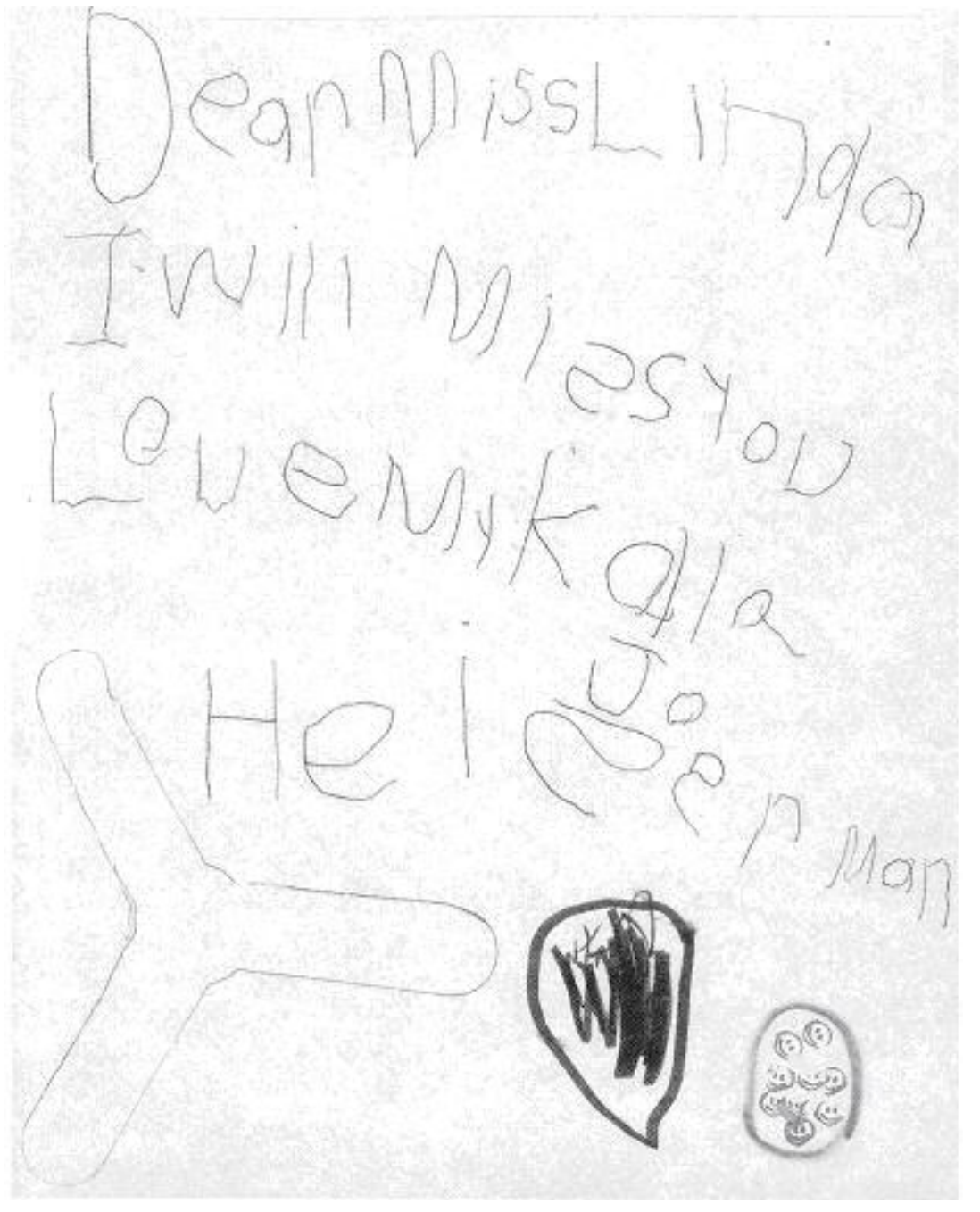

Fig. 3. By the end of the semester, Mykala has bounded into literacy, as seen in this farewell letter to her teacher. Linda. Over the semester she has practiced and experimented on a daily basis, gradually replacing her curlicues and drawings with letters and words. now wants to make a house with a door that opens and closes easily and that swings open as one goes through. Talking over this problem with her teacher and friends, she obtains a shoe box. She cuts out a door and windows, decorates the house, and fills it with furniture and people. By this point the child has gained a great deal of experience through her explorations of the three different materials for representing her house.

This example illustrates the idea that different materials, because of their different qualities, make it easier or harder to "say" a certain message. Paint is fluid, emotionally evocative, and easy to apply, but once on the paper, hard to modify. Clay is soft, easily manipulated and changed, but tends to be squishy and to fall apart when handled. Cardboard is rigid and buildable but harder for the young child to work with. Each medium has different affordances, to use a term borrowed from the perception theory of J. J. Gibson (1979): "An affordance is the relationship between the transformable properties of a medium and the child's desire to use that property to make symbols" (Forman, 1994, p. 38).

Affordances are possibilities for action on the environment that depend on the person or actor: An object or material has different affordances for different people at different times. A telephone affords communication if the caller knows how to use the phone and also can hear and speak, but also could afford protection if the caller were suddenly attacked and had no better weapon to protect himself! E. J. Gibson (1991) suggested that affordances are among the first properties of the environment that the infant notices and differentiates in perceptual development. Perceptual development from the beginning involves a constant discrimination among sensory perceptions and a search for meaning that specifies the events, layouts, and objects of the world (E. J. Gibson, 1991, p. 493). 
Such learning helps children's perceptual capacities to become progressively refined, graded, and educated, and provides necessary foundation for emergent cognitive skills related to the decoding and encoding tasks of later literacy.

Thus, as young children work with different materials, they come to learn about and appreciate their affordances. Each material invites and offers possibilities that orient children in certain directions when they use it. They take advantage of its special strengths and make compromises with its limitations. For example, seeking to make a fort, they may search for blankets and chairs. knowing how easy it is to drape the blankets over the backs of the chairs and how dark and inviting will be the crawl spaces within; at the same time, they know that the blankets slide off easily and so they need to anchor them with heavy objects.

Ceppi and Zini (1998) provide a systematic technical view of how architects working with Reggio educators conceive of the school environment. Materials can be described in terms of their color dimensions, tactile qualities, and time/space distribution. Some of the polar dimensions along which materials differ and offer affordances for children are large-scale versus small-scale: discontinuous (modular) versus continuous; bounded (enclosed) versus unbounded; permanent (lasting) versus disappearing (vanishing); wet versus dry; hard versus soft; sharp versus blunted; rough versus smooth; dark versus light; shiny versus dull; opaque versus transparent; and plentiful versus rare.

The Reggio educators take advantage of these affordances when helping children record and communicate their ideas. For example, Laura Rubizzi of the Diana School told an American study group in May 1997, about her conversation with children concerning where angels come from and how they fly.
She related that she had asked children to draw their initial ideas about angels with felt-tip pens. They drew many evocative images. One child drew a butterfly with an angel face. Another drew her beloved grandmother, who had recently died, as a figure planted in the ground and now sprouted into a tree. Another child drew a shadow of an ascending girl (perhaps herself), rising to meet the figure of a descending angel. The children productively shared these initial ideas but then wanted more ways to act out some of the wishes and images suggested by their talk and drawings. They decided to go to the computer to send a message, in their words, "to the Great Beyond" (perhaps the mystery of the computer's technology made it seem the most appropriate means for sending a message into unknown space). Laura now realized that the children had many more theories about angels than they could represent through drawing. Therefore, after school she glued the children's angel drawings onto stiff paper and cut them out with scissors (a task too difficult for the children). This allowed the children to play actively with their figures, moving them into any position relative to one another and within an imaginary space. As they manipulated their angels, Laura replayed the tape recordings of their initial descriptions and musings. Hearing their theories again, the children began new, more complex drawings. Their ideas continued to develop concerning notions of time, life, infinity, death, and the origins of life on earth. [See "A rustling of wings," in The Hundred Languages of Children Exhibit Catalog, (Reggio Children, S.r.l. 1996), pp. 194-197].

It is clear that going between different media allows children to confront and solve different problems as they progress through a project. For instance, words and gestures are excellent at the initial stage for brainstorming and sharing, and so 
are felt-tip pens for quick and vivid composing and comparing of first ideas. At a later stage, other materials, easily modified and revised, are good for conferring, planning, and designing, such as blocks for laying out a city, and pencil drawings and graph paper for making diagrams. At the concluding stage, children benefit from media they can use to create beautiful products with maximum audience impact and thereby make bold, summarizing statements (high quality paints, glossy papers, artist-quality clays, fine collage materials). As children brainstorm, observe, plan, and create, they learn most by alternating through different media in a cycle of symbolization (Forman, 1993, 1994). Malaguzzi (1998) summed this up in a vivid way:

As they go from one symbolic language to another, the children find that each transformation generates something new. This complicates the situation and advances them. As they construct their idea, they also construct the symbols and a plurality of codes. ... With each step, the child goes farther and higher, as a spaceship with several stages, each pushing the rocket deeper into space, (p. 92)

\section{Suggestions for Teachers}

What are the implications of these insights for the teachinglearning process? Many suggestions arise from the analysis presented in this paper.

- Select one or two unusual "literacies" to become specializations for your classroom, such as photography, clay, or drama, and interweave them throughout your curriculum and across the whole school year.

- Encourage children from preschool through primary grades to design and create complex products and pro- ductions that involve multiple symbolic languages and long-term project work (Edwards \& Springate, 1993, 1996).

- Set up a resources studio in a protected area of the classroom or an easily accessible closet, with many materials and resources displayed in an organized, inviting, and distinctive way. Get children involved in sorting and arranging the materials. Seek a rich and provocative assortment of natural and manufactured materials-bought, gathered, recycled, and donated-of high quality and with complex affordances. Teach children how to use the collection respectfully but also with pleasure (Topal \& Gandini, 1999).

- Offer children unusual combinations of materials to stimulate their imagination and problem solving. One morning you might set up a light table by placing upon it a vase of pussy willows, basket of leaves and grasses collected by the children, and transparent papers nearby, with water colors. Another day, place scissors, pieces of colored paper, and plastic transparent jewels or costume jewelry and ribbons (Cadwell, 1997).

- Help children gain broader knowledge of the properties of different materials by giving them many opportunities to experiment over time. For example, present cornstarch and water in different formats such as in small bowls on separate trays, in one large bowl, in sealed sandwich bags, or mixed with something unexpected like marbles. When children are finished using a material, review with them what they did and what problems they encountered (Seefeldt, 1994). 
- Help children gain skill and control in multiple symbolic languages by means of graded exploration and experimentation and child-centered planning, accompanied by appropriate skill-teaching, scaffolding, and modeling (Dighe, Calomiris, \& Van Zutphen, 1998).

- Take photos to document children's uses of materials and place these on public display to elicit conversations with children. Some can be laminated for easy handling or made into a booklet. Invite children to tell others about what they have done, and help them clarify what materials they used at each stage of a project or activity (Carter \& Curtis, 1996; Helm, Beneke, \& Steinheimer, 1998; Jackson, 1994).

- Initiate activities that invite children's families to experience with their children the power of integrating visual and verbal literacies. Hunt (1996) circulated books among the families of her kindergarten children along with notebooks for the parents and children to record and share comments and drawings inspired by the book.

- Reach out and connect children with community artists and quality creative products and productions combining multiple symbol systems, notations, or technologies. In appropriate ways, help children understand how they interpret complex products and combine the intersecting messages from multiple aspects ("reading the third text").

\section{Conclusion}

An integrated arts curriculum has long been favored by many educators, but today there are more reasons than ever to implement such a philosophy. From communications theory comes a new understanding of how modern technologies demand that children learn to "read" and "write" messages involving complex combinations and integrations of visual and verbal formats. From psychology come insights about intelligence being multiple not unitary, as well as ecological perception theory offering a well-accepted framework for analyzing the affordances and expressive possibilities of different media. From education come fresh approaches to integrated curriculum, including a philosophy and pedagogy from Reggio Emilia, Italy, that combines well with current thinking by North Americans. Altogether, we have many rationales and exciting strategies at hand for launching young children toward an integrated visual and verbal literacy that involves substance, challenge, and discipline, as well as innovation, creativity, and freedom.

\section{Acknowledgments}

An earlier version of this paper was presented at the "Early Childhood Conference on Literacy and Numeracy in 0-8 Year Olds," University of Strathclyde, Scotland, November 1997. The writing of this paper was partially supported by the Institute for Agricultural and Natural Resources, University of Nebraska, Lincoln, Journal Series 12437. 


\section{References}

Cadwell, L. B. (1997). Bringing Reggio Emilia home: An innovative approach to early childhood education. New York: Teachers College Press.

Carter, M., \& Curtis, D. (1996). Spreading the news: Sharing the stories of early childhood education. St. Paul, MN: Redleaf.

Ceppi, G., \& Zini, M. (Eds.). (1998). Children, spaces, relations-Metaproject for an environment for young children. Reggio Emilia, Italy: Reggio Children S.r.1.

Dighe, J., Calomiris, Z., \& Van Zutphen, C. (1998). Nurturing the language of art in children. Young Children, 53( 1), 4-9.

Edwards. C. P. (1999). Generations of families: A teaching project and photograph exhibition. Journal of Family and Consumer Sciences: From Research to Practice, 91(1), 105- III.

Edwards, C. P., \& Springate. K. (1993). Inviting children into project work. Dimensions of Early Childhood, 22(1). 9-12-40.

Edwards, C. P.. \& Springate, K, (1996). The lion comes out of the stone: Promoting creative expression in young children, Dimensions of Early Childhood. 24(1). 24-29.

Forman, G. (1993). Multiple symbolization in the Long Jump Project In C. P. Edwards, L. Gandini. \& G. Forman (Eds.). The hundred languages of children: The Reggio Emilia approach to early child hood education (pp. 171-188). Stamford, CT: Ablex.

Forman, G. (1994). Different media, different languages. In L. G. Katz \& B. Cesarone (Eds.), Reflections on the Reggio Emilia approach (pp. 41-54). Chicago: ERIC Clearinghouse on Elementary and Early Childhood Education.

Gardner, H. (1998). Extraordinary cognitive achievements (ECA): A symbol systems approach. In R. M. Lerner (Ed.), Handbook of child psychology. (5th ed., Vol. 1). Theoretical models of human development (pp. 415-466). New York: Wiley.
Garrett-Petts, W. F. \& Lawrence, D. (1996). Integrating visual and verbal literacies. Winnipeg, Manitoba: Inkshed Publications.

Gibson, E. J. (1991). An odyssey in learning and perception. Cambridge, MA: Harvard University Press.

Gibson, J. J. (1979). The ecological approach to visual perception. Boston, MA: Houghton-Mifflin.

Helm, J. D., Beneke, S.. \& Steinheimer. K. (1998). Windows on learning: Documenting young children's work. New York: Teachers College Press.

Hunt, A. (1996). Reading and writing pictures: Literacy conversations in an early years community. In W. F. Garrett-Petts \& D. Lawrence (Eds.). Integrating visual and verbal literacies (pp. 35-39). Winnipeg, Manitoba: Inkshed Publications.

Jackson, M. (1994). Creative display and environment. Portsmouth, NH: Heinemann.

Lally, J. R. (1998). Brain research, infant learning, and child care curriculum. Child Care Information Exchange, 5/98,46-48.

Malaguzzi, L. (1998). History, ideas, and basic philosophy. In C. P. Edwards, L. Gandini, \& G. Forman (Eds.), The hundred languages of children (2nd ed.): The Reggio Emilia approach, advanced reflections (pp. 49-198). Stamford, CT: Ablex.

Reggio Children, S.r.1. (1996). The hundred languages of children: Narratives of the possible. Exhibit Catalog. Distributed by Reggio Children USA, Washington, DC 20005-3105.

Seefeldt, C. (1995). Art-serious work. Young Children. 41(5), 3-7. Topal, C. W., \& Gandini. L. (1999). Beautiful stuff! Learning with found materials. Worcester, MA: Davis Publications. 